\title{
Immunological Criteria for Differential Diagnosis of Hypertension in Pregnant Women
}

\author{
DOI: 10.17691/stm2015.7.3.15
}

Received March 4, 2015

I.A. Panova, MD, DSc, Head of the Department of Obstetrics and Gynecology;

A.I. Malyshkina, MD, DSc, Director;

D.A. Khlipunova, Junior Researcher, Department of Obstetrics and Gynecology;

E.A. Rokotyanskaya, MD, PhD, Researcher, Department of Obstetrics and Gynecology;

L.A. Sytova, MD, PhD, Associate Professor, Department of Obstetrics and Gynecology, Neonatology, Anesthesiology and Reanimatology;

A.V. Kudryashova, DSc, Senior Researcher, Laboratory of Clinical Immunology

Ivanovo Research Institute of Motherhood and Childhood named after V.N. Gorodkov, Ministry of Health of the Russian Federation, 20 Pobeda St., Ivanovo, 153045, Russian Federation

The aim of the investigation was to study expression characteristics of neutrophil and monocyte adhesion molecules (CD49b, CD11b, CD51 and CD99) in the venous blood of pregnant women with various hypertensive disorders and on the basis of these findings to find new criteria for differential diagnosis and to develop a diagnostic algorithm for the given pathology.

Materials and Methods. The study involved 205 women at 20-34 weeks' gestation: 62 women with preeclampsia (PE), 44 women with chronic arterial hypertension (CAH), 44 women with $\mathrm{CAH}$ and secondary PE, 55 women without hypertensive disorders. The concentration of

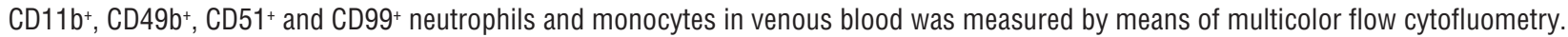

Results. As compared to the control group the level of $\mathrm{CD} 49 \mathrm{~b}^{+}$neutrophils was the highest in women with PE and CAH with secondary PE, the content of CD99+ neutrophils was higher in pregnant women with $\mathrm{CAH}$ and $\mathrm{CAH}$ with secondary $\mathrm{PE}$, and the level of CD51+ neutrophils and $\mathrm{CD} 11 \mathrm{~b}^{+}$monocytes appeared to be lower in pregnant women with $\mathrm{CAH}$. In contrast to the group of women with CAH, in case of PE increase of CD49b+ and CD99+ neutrophils as well as CD11 b+ monocytes was observed. Unlike pregnant women with CAH, women with CAH and secondary PE showed increase in CD49b+ neutrophils, CD11 b+ monocytes and, unlike PE women, increase in CD99+ neutrophils. Using ROC-analysis of parameters under study we identified new immunological criteria for diagnosing various hypertensive disorders in pregnancy and developed a differential diagnostic algorithm of the given pathology.

Conclusion. Changes in concentration of $\mathrm{CD}_{11} \mathrm{~b}^{+}, \mathrm{CD} 49 \mathrm{~b}^{+}$and $\mathrm{CD} 99^{+}$neutrophils and monocytes in venous blood of pregnant women with hypertension may be regarded as additional differential diagnostic criteria for identifying its nosological form, which enables to determine patient managing tactics, as well as timely and differential approach to therapy.

Key words: preeclampsia; hypertension in pregnancy; adhesion molecules.

Arterial hypertension in pregnant women is one of the most common and dangerous medical disorders. In the Russian Federation the incidence rate of edema, proteinuria and hypertensive disorders in pregnant women was $17.4 \%$ among new mothers in 2011 , and $16.7 \%$ in 2012 [1].

The term "hypertension in pregnancy" covers a wide range of disorders: chronic arterial hypertension $(\mathrm{CAH})$, gestational hypertension, preeclampsia (PE), CAH with secondary preeclampsia [2]. According to the literature data, PE amounts to $5-7 \%$ of pregnancy complications, $\mathrm{CAH}$ is observed in $1-5 \%$ of pregnant women and preeclampsia secondary to $\mathrm{CAH}$ occurs in 17.7$32.1 \%[3,4]$.

In clinical practice it is often difficult to make a differential diagnosis of arterial hypertension character in pregnancy due to several reasons. Arterial pressure monitoring is not often carried out in many women even in a pregravid stage, revealing $\mathrm{CAH}$ only during pregnancy, which increases the risk of unfavorable perinatal outcomes. Besides, physiological hypotension in pregnancy and suppressed oligosymptomatic PE course can impede timely diagnosis and assessment of pathology severity.

Correct diagnosis and differential approach to selecting hypotensive therapy are important factors in choosing the tactics of managing pregnant women with $\mathrm{AH}$. In various hypertensive disorders treatment approaches differ considerably, demanding the search of new differential diagnostic criteria for these disorders in pregnancy.

In recent years the following methods are widely used for differential diagnosis of hypertensive disorders in pregnant women: 24 -hour arterial pressure monitoring [5, 6], echocardiography [7], identifying hemodynamics type [7], microalbuminuria [8], glomerular filtration rate [7], the

For contacts: Khlipunova Daria Aleksandrovna, e-mail: da_shutka_xa@mail.ru 
level of angiogenic factors (VEGF, PIGF, sFIt-1, sEng) [9], total and fetal DNA in maternal blood plasma [10], neurospecific proteins in the placenta tissue (NSE $n$ GFAP) [11], and others.

Nowadays many researchers consider hypertension in pregnancy to be a manifestation of generalized damage of vascular endothelium resulting in the impairment of vasoactive properties of blood vessels and their permeability [12]. Endotheliosis, in its turn, combines with changes in immunological processes [13]. This is accompanied by increasing functional activity of leucocytes and lymphocytes, complement system activation, changes in cytokine profile with proinflammatory fractions prevalence [14-17]. As a result of growing systemic inflammatory reaction, adhesion molecules expression on endotheliocytes and circulating blood cells increases, promoting further activation, mobilization and extravasation of leucocytes [17, 18].

The aim of the investigation was to study expression characteristics of neutrophil and monocyte adhesion molecules (CD49b, CD11b, CD51 and CD99) in the venous blood of pregnant women with various hypertensive disorders and on the basis of these findings to find new criteria for differential diagnosis and to develop a diagnostic algorithm for the given pathology.

Materials and Methods. The study involved 205 women at 20-34 weeks' gestation: 62 women with PE (group 1), 44 women with CAH (group 2), 44 women with CAH and secondary PE (group 3), 55 women composed a control group (uncomplicated pregnancy without hypertensive disorders). The study was performed at the Obstetric Clinic of Ivanovo Research Institute of Motherhood and Childhood named after V.N. Gorodkov.

Criteria for women to be included in the study were hypertensive disorders of different origin and severity in pregnancy. Pregnant women were selected into groups according to the Federal Clinical Guidelines "Hypertensive disorders in pregnancy, at labor and in the postnatal period. Preeclampsia. Eclampsia" (2013). The study complies with the Declaration of Helsinki (adopted in June 1964 (Helsinki, Finland) and revised in October 2000 (Edinburgh, Scotland)) and approved by the local ethics committee. All patients gave informed consent to participate in the study.

Patients with acute inflammatory diseases and exacerbation of their chronic stages, allergic reactions at the time of examination, tumors of different localization, systemic connective tissue diseases, chronic renal insufficiency, symptomatic arterial hypertension were excluded from the study.

Mean age of pregnant women with $\mathrm{CAH}(32.7 \pm 0.7$ years) and those with CAH and PE ( $31.8 \pm 0.8$ years) was statistically significantly older than in the control group (27.3 \pm 1.2 years) $(p=0.01$ and $p=0.03$, respectively) and in the group of women with $P E(28.8 \pm 0.7$ years) $(p=0.001$ and $p=0.01$, respectively).
In terms of extragenital pathology, all pregnant women with hypertensive disorders showed higher incidence rate of urinary tract diseases ( $p<0.05$ in all cases), biliary disorders ( $p<0.05$ in all cases) and obesity $(p<0.05$ in all cases) as compared to the control group. The number of women with a family history of hypertension (burdened heredity) was significantly higher in groups 2 and 3 as compared to group 1 and the control group $(p<0.05$ in all cases). Menstrual disorders in the past history were observed significantly more often in women from groups 2 and 3 than in the control group $(p=0.001$ and $p=0.01$, respectively). Pregnant women from groups 1 and 3 had a greater number of legal abortions in the past medical history in contrast to the control group ( $p=0.03$ and $\mathrm{p}=0.04$, respectively).

Fetoplacental insufficiency with uterine-placental and fetal-placental misperfusion, fetal growth restriction and anemia $(p<0.05$ in all cases as compared to the control group) were the most common gestation complications in pregnant women with hypertensive disorders. The incidence of premature induced delivery was the highest in women of groups 1 and 3 in contrast to group 2 and the control group ( $p<0.05$ in all cases). Mean gestational term by the time of delivery in PE women was $32.83 \pm 0.75$ weeks, in CAH and secondary PE women $33.12 \pm 0.47$ weeks, which was significantly different from the group with uncomplicated pregnancy and $\mathrm{CAH}$ group, where the term of delivery equaled $39.13 \pm 0.27$ and $37.16 \pm 0.33$ weeks, respectively $(p<0.05$ in all cases). Cesarean section was most often performed in patients from groups $1(86.02 \%)$ and $3(84.13 \%)$ as compared to group $2(62.86 \%)$ and the control group $(24.00 \%)(p<0.05$ in all cases). The incidence of neonatal asphyxia, subsequent emergency treatment in the neonatal resuscitation unit and low weight/length indices at birth were significantly higher in PE patients' babies and those delivered by women with PE secondary to $\mathrm{CAH}$, in contrast to patients with $\mathrm{CAH}$ and physiological pregnancy $(\mathrm{p}<0.05$ in all cases).

Peripheral venous blood was used for laboratory tests. Separation of the total leukocyte fraction was performed using Ficoll-Urographine density gradient $(d=1.114)$ centrifugation method. Monocyte and neutrophil phenotype was studied by means of multicolor flow cytometry using FACSCanto ${ }^{\mathrm{TM}}$ II device (Becton Dickinson, USA). The results were analysed with FACSDiva ${ }^{\mathrm{TM}}$ software. Relative concentration of

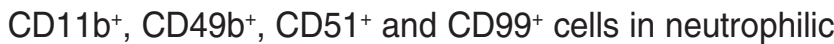
$\left(\mathrm{CD} 14^{-} \mathrm{CD} 45^{+}\right)$and monocytic $\left(\mathrm{CD} 14^{+} \mathrm{CD} 45^{+}\right)$gates was determined. Cell staining and fixation was performed in a standard way according to the manufacturer's instructions.

The obtained results were statistically analysed using applied licensed software package Microsoft Office 2010, Statistica 6.0 and MedCalc v7.4.4.1. Quantitative values were expressed as mean \pm standard error of mean $(\mathrm{M} \pm \mathrm{m})$. To test statistical hypotheses on the type 
of distribution Shapiro-Wilk criterion was used. In all cases distribution of variables corresponded to the law of normal distribution. Significance of differences between the values in independent samples was evaluated using Student t-criterion (significance level $p<0.05$ was regarded as statistically significant). To obtain numeric values of clinical significance of the tests ROC-analysis was used. Quantitative interpretation of ROC-analysis data was made using AUC, that is the area under the ROC-curve restricted by this curve and the axis of false negative classifications proportion.

Results and Discussion. Analysis of the data obtained from the study showed statistically significant increase in the level of $\mathrm{CD}_{4} \mathrm{~b}^{+}$cells in neutrophil population in pregnant women with $\mathrm{PE}$ and $\mathrm{CAH}$ secondary to $\mathrm{PE}$ as compared to the control group $(p=0.01$ and $p=0.0001$, respectively) (See the Table). The concentration of $\mathrm{CD}^{+} 9^{+}$cells in the neutrophil population increased in pregnant women with $\mathrm{CAH}$ and $\mathrm{CAH}$ secondary to $\mathrm{PE}$ as compared to the control group ( $p=0.003$ and $p=0.002$, respectively). In contrast to the control, the level of $\mathrm{CD} 51^{+}$cells in the neutrophil population $(p=0.04)$ and $C D 11 b^{+}$cells in the monocyte population $(p=0.03)$ significantly decreased in pregnant women with $\mathrm{CAH}$.

It was established that unlike $\mathrm{CAH}$ women, in $\mathrm{PE}$ group significant increase in $\mathrm{CD}_{4} \mathrm{~b}^{+}(\mathrm{p}=0.002)$ and $\mathrm{CD}^{2} 9^{+}(p=0.002)$ neutrophil concentration as well as higher $\mathrm{CD} 11 \mathrm{~b}^{+}$monocyte count $(\mathrm{p}=0.01)$ were observed. In women with $\mathrm{CAH}$ and secondary PE the concentration of $\mathrm{CD} 49 \mathrm{~b}^{+}$neutrophils and $\mathrm{CD} 11 \mathrm{~b}^{+}$monocytes increased, in contrast to $\mathrm{CAH}$ women without PE $(\mathrm{p}=0.0001$ and $\mathrm{p}=0.02$, respectively), the level of $\mathrm{CD} 99^{+}$neutrophils was observed to increase as well, in contrast to pregnant PE women $(p=0.001)$. We revealed no significant differences in the expression of CD51 molecules by neutrophils and monocytes between the groups of women with hypertensive disorders ( $p>0.05$ in all cases).

Alterations revealed in the expression of CD11b, CD49b, CD51 and CD99 molecules in pregnant women with hypertension demonstrate enhanced adhesion properties of neutrophils and monocytes manifesting themselves to a greater extent in preeclampsia. Alterations of adhesion molecule expression by peripheral phagocytes are multidirectional in a number of cases and reflect the peculiarities of pathogenetic mechanisms of developing hypertension in preeclampsia and essential hypertension. CD49b and CD11b molecules are known to contribute to a strong cell adhesion and provide leukocyte spreading on the endothelium [19] with their subsequent extravasation by binding to the receptors of extracellular matrix proteins [20]. Increasing number of cells expressing these integrins reflects the process of their activation and mobilization in systemic inflammatory reaction characteristic of preeclampsia [21].

In case of $\mathrm{CAH}$ we noticed no significant changes in the concentration of $\mathrm{CD} 49 \mathrm{~b}^{+}$cells but revealed statistically significant increase in the level of $\mathrm{CD} 9^{+}$ neutrophils. CD99 molecules participate in the direct transendothelial migration of leukocytes to perivascular space [20]. Increase in the concentration of $\mathrm{CD} 9^{+}$ neutrophils in chronic hypertension is likely to result in a growing pool of migrating leukocytes and phagocyte accumulation in perivascular tissue of blood vessels, which has been described in a number of researches [18]. It also leads to chronic inflammation development in which the process of neutrophil adhesion to endothelium does not depend on $\beta_{2}$ integrins but it is rather provided by $\alpha_{4}$ integrins [22].

To determine the most sensitive and specific criteria for diagnosis of various hypertensive disorders in pregnant women the ROC-analysis revealed that the most informative differential indices for $\mathrm{PE}$ and $\mathrm{CAH}$ were the concentration of $\mathrm{CD}_{11} \mathrm{~b}^{+}$monocytes $(\mathrm{AUC}=0.832$; sensitivity $-74.2 \%$; specificity - $85.7 \%$; border-line $80 \%$ ) and CD99+ neutrophils (AUC $=0.770$; sensitivity 95.7\%; specificity - 52.9\%; border-line - 53\%). The most accurate criteria for differential diagnosis of PE and $\mathrm{PE}$ secondary to $\mathrm{CAH}$ were the concentration of CD49b+ neutrophils ( $A \cup C=0.770$; sensitivity $-88.9 \%$; specificity - 61.5\%; border-line - 70.5\%) and $\mathrm{CD}^{2}{ }^{+}$neutrophils (AUC $=0.766$; sensitivity $-62.0 \%$; specificity $-72.0 \%$; border-line - 51\%). For differential diagnosis of $\mathrm{CAH}$ and $\mathrm{CAH}$ with $\mathrm{PE}$ the most accurate criteria appeared to be the level of $\mathrm{CD} 11 \mathrm{~b}^{+}$monocytes (AUC=0.801; sensitivity - 68.2\%; specificity $-76.2 \%$; border-line $-80.5 \%$ ) and $\mathrm{CD} 49 \mathrm{~b}^{+}$neutrophil count (AUC=0.893; sensitivity - 88.5\%; specificity - 91.7\%; border-line $-73 \%)$. Relying on the identified border-

The indices of relative concentration of neutrophils and monocytes expressing adhesion molecules in pregnant women with hypertensive disorders

\begin{tabular}{|c|c|c|c|c|c|}
\hline \multicolumn{2}{|c|}{ Index (\%) } & Control & САН & CAH with PE & PE \\
\hline \multirow{2}{*}{ CD11b $^{+}$} & neutrophils & $79.57 \pm 2.26$ & $83.24 \pm 2.40$ & $81.78 \pm 1.93$ & $83.00 \pm 1.62$ \\
\hline & monocytes & $81.60 \pm 1.84$ & $76.74 \pm 1.43^{*}$ & $80.79 \pm 1.49^{v}$ & $81.41 \pm 1.30^{\mathrm{w}}$ \\
\hline \multirow{2}{*}{$\mathrm{CD}_{49 \mathrm{~b}^{+}}$} & neutrophils & $54.01 \pm 3.30$ & $57.78 \pm 2.78$ & $75.19 \pm 2.84^{\star \star \star * v v t+}$ & $65.13 \pm 2.27^{\star \star v}$ \\
\hline & monocytes & $91.83 \pm 1.75$ & $94.50 \pm 1.37$ & $88.07 \pm 3.40$ & $92.22 \pm 1.74$ \\
\hline \multirow{2}{*}{$\mathrm{CD} 1^{+}$} & neutrophils & $54.68 \pm 4.60$ & $40.37 \pm 5.28 *$ & $47.17 \pm 5.79$ & $45.55 \pm 4.83$ \\
\hline & monocytes & $75.13 \pm 4.44$ & $80.37 \pm 4.57$ & $72.35 \pm 6.96$ & $81.93 \pm 2.10$ \\
\hline \multirow{2}{*}{ CD99 $^{+}$} & neutrophils & $35.21 \pm 4.39$ & $53.85 \pm 3.97^{* *}$ & $58.12 \pm 5.15^{\star \star++}$ & $37.12 \pm 2.96^{w v}$ \\
\hline & monocytes & $88.55 \pm 1.28$ & $90.10 \pm 1.70$ & $84.22 \pm 4.20$ & $88.75 \pm 2.08$ \\
\hline
\end{tabular}

Note. Statistically significant difference in values with control group: * $p<0.05,{ }^{* *} p \leqslant 0.01$, ${ }^{* * *} p \leqslant 0.001$; with CAH group: ${ }^{v} p<0.05,{ }^{v v} p \leqslant 0.01$, vv $p \leqslant 0.001$; with PE group: ${ }^{+} p \leqslant 0.01$, ${ }^{++} \mathrm{p} \leqslant 0.001$. $\mathrm{CAH}$ : chronic arterial hypertension; PE: preeclampsia. 


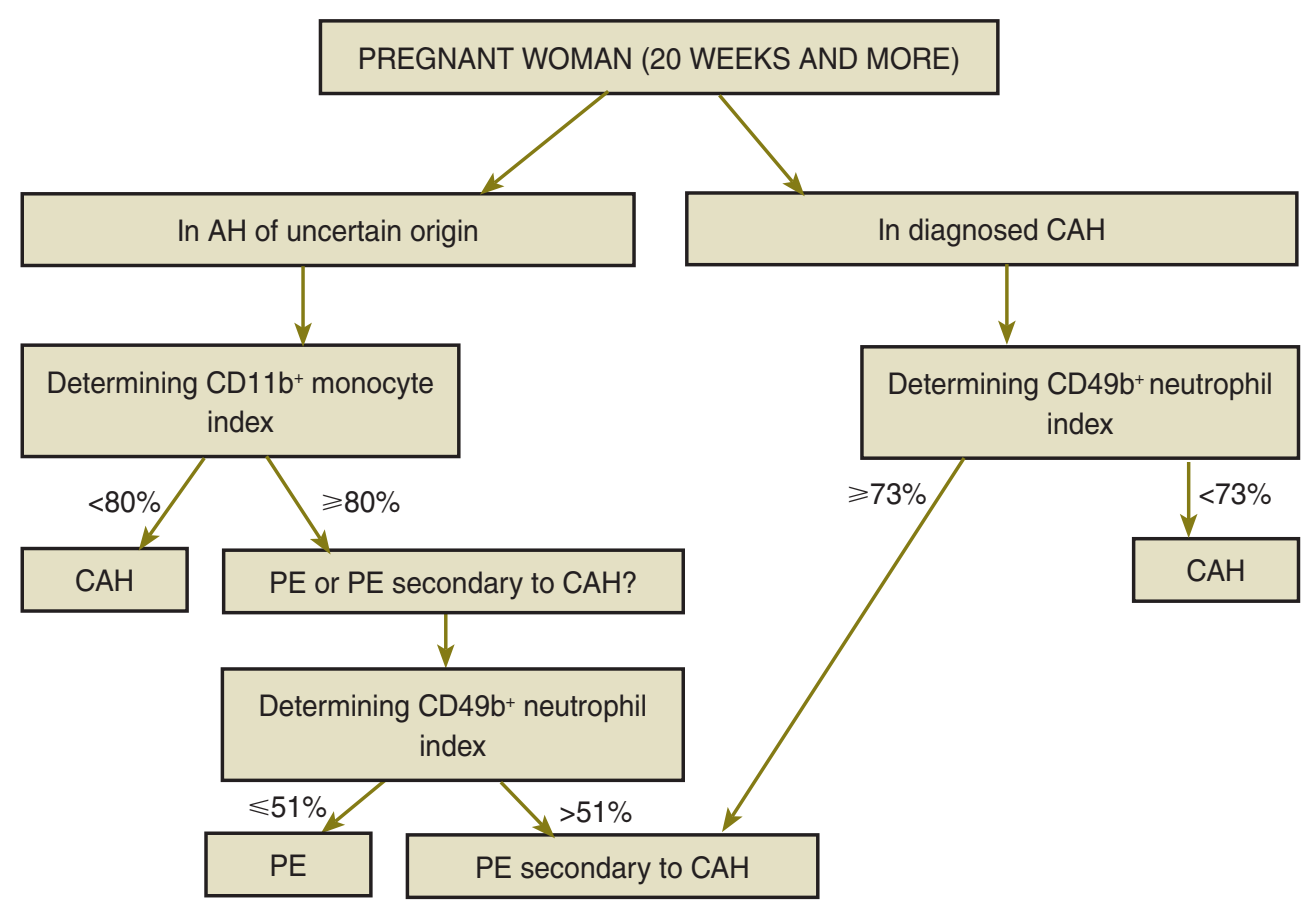

Algorithm for differential diagnosis of hypertensive disorders in pregnant women. $\mathrm{CAH}$ : chronic arterial hypertension; PE: preeclampsia

line criteria of relative $\mathrm{CD}_{49} \mathrm{~b}^{+}$cell concentration in neutrophil population "Method of diagnosing preeclampsia in pregnant women with chronic arterial hypertension" was elaborated (certificate of receipt of RF No.2014125409 of 24.06.2014).

The undertaken studies make it possible to suggest new diagnostic criteria for various hypertensive disorders in pregnant women and to develop a diagnostic algorithm for the given pathology (See the Figure).

To specify arterial hypertension character in pregnant women with hypertension of unclear genesis after 20 weeks' gestation the authors suggest determination of $\mathrm{CD}_{11 \mathrm{~b}^{+}}$monocytes concentration. If the value is lower than $80 \%, \mathrm{CAH}$ is diagnosed. For patients with CD11 $\mathrm{b}^{+}$monocyte concentration of $80 \%$ or more it is recommended to determine the concentration of $\mathrm{CD} 9^{+}$ neutrophils to differentiate $\mathrm{PE}$ from $\mathrm{PE}$ secondary to $\mathrm{CAH}$. If the value is equal or lower than $51 \%$, the diagnosis of $\mathrm{PE}$ should be made. If the concentration exceeds $51 \%$, PE secondary to $\mathrm{CAH}$ is established. In case of previously diagnosed $\mathrm{CAH}$ it is recommended to determine the level of $C D 49 b^{+}$neutrophils to find out whether preeclampsia occurred later. If this index is higher than $73 \%$, a diagnosis of $\mathrm{PE}$ is established for this category of women.

Conclusion. Changes in the concentration of neutrophils and monocytes expressing CD11b, CD49b and CD99 molecules in the venous blood of pregnant women with hypertension may be used as additional differential diagnostic criteria for identifying its nosology, enabling to determine the tactics of patient management, and to choose the adequate therapy timely and differentially.

Study Funding. This study was supported by the grant No.MK-6885.2015.7 of the President of the Russian Federation.

Conflicts of Interest. The authors have no conflict of interests to disclose.

\section{References}

1. Osnovnye pokazateli zdorov'ya materi i rebenka, deyatel'nost' sluzhby okhrany detstva i rodovspomozheniya $v$ Rossiyskoy Federatsii [Main indices of mother and child health, work of child welfare and marternity obstetric services in the Russian Federation]. Moscow; 2013, URL: http:// medlan.samara.ru/sites/default/files/upload_files/upload_files/ rodovspomozhenie_2013_0.pdf.

2. Mezhdunarodnaya statisticheskaya klassifikatsiya bolezney $i$ problem, svyazannykh so zdorov'em. Desyatyy peresmotr [International statistical classification of diseases and related health problems. $10^{\text {th }}$ revision]. Moscow: Meditsina; 2003; $2466 \mathrm{p}$.

3. Vigil-De Gracia P., Montufar-Rueda C., Smith A. Pregnancy and severe chronic hypertension: maternal outcome. Hypertens Pregnancy 2004; 23(3): 285-293, http://dx.doi. org/10.1081/prg-200030315.

4. Audibert F., Benchimol Y., Benattar C., Champagne C., Frydman R. Prediction of preeclampsia or intrauterine growth restriction by second trimester serum screening and uterine Doppler velocimetry. Fetal Diagn Ther 2005; 20(1): 48, http:// dx.doi.org/10.1159/000081369.

5. Murashko L.Ye., Serov V.N., Tkacheva O.N., Tumbayev I.V. 24-hour blood pressure monitoring in the diagnosis and treatment of hypertensive syndrome in gestosis 
and hyper tensive disease in pregnant females. Akusherstvo $i$ ginekologiya 2007; 3: 13-17.

6. Steyn D.W., Odendaal H.J., Hall D.R. Diurnal blood pressure variation in the evaluation of early onset severe preeclampsia. Eur J Obstet Gynecol Reprod Biol 2008; 138(2): 141-146, http://dx.doi.org/10.1016/j.ejogrb.2007.08.010.

7. Chicherina E.N., Padyganova A.V. The structural and functional characteristics of the cardiovascular system and kidneys in pregnant women with chronic arterial hypertension in the presence and absence of obesity. Rossiiskii vestnik akushera-ginekologa 2012; 1: 48-52.

8. Spaan J.J., Ekhart T., Spaanderman M.E., Peeters L.L. Remote hemodynamics and renal function in formerly preeclamptic women. Obstet Gynecol 2009; 113(4): 853-859, http://dx.doi.org/10.1097/AOG.0b013e31819cafOf.

9. Buhimschi C.S., Norwitz E.R., Funai E., Richman S., Guller S., Lockwood C.J., Buhimschi I.A. Urinary angiogenic factors cluster hypertensive disorders and identify women with severe preeclampsia. Am J Obstet Gynecol 2005; 192(3): 734741, http://dx.doi.org/10.1016/j.ajog.2004.12.052.

10. Logutova L.S., Rad'kov O.V., Kalinkin M.N., Zavarin V.V. The circulation of fetal extracellular deoxyribonucleic acid in the plasma of pregnant women and the formation of clinical and pathogenetic features of arterial hypertension in them. Rossiiskii vestnik akushera-ginekologa 2012; 2: 18-21.

11. Sidorova I.S., Nikitina N.A., Unanyan A.L., Rzayeva A.A., Kinyakin V.V. Pathogenetic rationale for a differentiated approach to managing pregnant women with arterial hypertension and preeclampsia. Akusherstvo $i$ ginekologiya 2013; 2: 35-40.

12. Sánchez-Aranguren L.C., Prada C.E., Riaño-Medina C.E., Lopez M. Endothelial dysfunction and preeclampsia: role of oxidative stress. Front Physiol 2014; 10(5): 372, http://dx.doi. org/10.3389/fphys.2014.00372.

13. Sidorova I.S., Gurina O.I., Milovanov A.P., Nikitina N.A., Bardachova A.V., Sheraanayeva T.V. The pathogenesis of gestosis as a manifestation of immunocomplex pathology of the endothelium (acute immune endotheliosis). Akusherstvo $i$ ginekologiya 2008; 6: 13-17.

14. Makarov I.O., Shemanaeva T.V., Gasanova S.R., Popova O.P. Gestosis as a manifestation of immune endotheliosis. Voprosy ginekologii, akusherstva $i$ perinatologii 2009; 6: 17-22.

15. Posiseeva L.V., Sotnikova N.Yu., Panova I.A., Kudryashova A.V., Antsiferova Yu.S., Kulida L.V. Immunnye mekhanizmy razvitiya gestoza [Immune mechanisms of gestosis development]. Ivanovo; 2008; 240 p.

16. Kudryashova A.V., Sotnikova N.Yu., Panova I.A., Kadyrova L.V. Differentiation of memory cells in the T-helper subset during normal pregnancy and preeclampsy. Zhurnal akusherstva i zhenskikh bolezney 2013; 2: 110-116.

17. De Ciuceis C., Rossini C., La Boria E., Porteri E., Petroboni B., Gavazzi A., Sarkar A., Rosei E.A., Rizzoni D. Immune mechanisms in hypertension. High Blood Press Cardiovasc Prev 2014: 21(4): 227-234, http://dx.doi.org/10.1007/ s40292-014-0040-9.

18. Filip M., Maciag J., Nosalski R., Korbut R., Guzik T. Endothelial dysfunction related to oxidative stress and inflammation in perivascular adipose tissue. Postepy Biochem 2012; 58(2): 186-194.

19. Liddington R.C., Bankston L.A. The structural basis of dynamic cell adhesion: heads, tails, and allostery. Exp Cell Res 2000; 261(1): 37-43, http://dx.doi.org/10.1006/excr.2000.5058.

20. Vestweber D. Molecular mechanisms that control leukocyte extravasation through endothelial cell contacts. Ernst Schering Found Symp Proc 2007; 3: 151-167, http://dx.doi. org/10.1007/2789_2007_063.

21. Bowen R.S., Moodley J., Dutton M.F., Fickl H. Systemic inflammatory indices in pre-eclampsia and eclampsia. J Obstet Gynaecol 2001; 21(6): 563-569, http://dx.doi.org/10.1080/0144 3610120085483.

22. Belotskiy S.M., Avtalion P.P. Vospalenie. Mobilizatsiya kletok i klinicheskie effekty [Inflammation. Cell mobilization and clinical effects]. Moscow: Binom press; 2008; 240 p. 